\title{
Nuclear magnetic resonance metabonomics reveals strong association between milk metabolites and somatic cell count in bovine milk
}

\author{
U. K. Sundekilde,$^{* 1}$ N. A. Poulsen, $\dagger$ L. B. Larsen, $†$ and H. C. Bertram* \\ *Department of Food Science, Kirstinebjergvej 10, DK-5792 Årslev, and \\ †Department of Food Science, Blichers Allé 20, DK-8830 Tjele, Faculty of Science and Technology, Aarhus University, Denmark
}

\begin{abstract}
Somatic cell count (SCC) is associated with changes in milk composition, including changes in proteins, lipids, and milk metabolites. Somatic cell count is normally used as an indicator of mastitis infection. The compositional changes in protein and fat affect milk coagulation properties, and also the metabolite composition is thought to contribute to differential milk properties. Milk somatic cells comprise different cell types, which may contribute to differential milk metabolite fingerprints. In this study, milk from a relatively large number of individual cows, representing significant differences in SCC, were analyzed by nuclear magnetic resonance (NMR)-based metabonomics, and the milk metabolite profiles were analyzed for differences related to SCC. Global principal component analysis performed on 876 samples from 2 Danish dairy breeds and orthogonal projection of latent structures discriminant analysis performed on a smaller subset (n $=70)$ representing high $\left(\mathrm{SCC}>7.2 \times 10^{5}\right.$ cells $\left./ \mathrm{mL}\right)$ and low $\left(\mathrm{SCC}<1.4 \times 10^{4}\right.$ cells $/ \mathrm{mL}$ ) milk SCC identified latent variables, which could be attributed to milk with elevated SCC. In addition, partial least squares regression between the NMR milk metabolite profiles and SCC revealed a strong correlation. The orthogonal projection of latent structures discriminant analysis and partial least squares regressions pinpointed specific NMR spectral regions and thereby identification of milk metabolites that differed according to SCC. Relative quantification of the identified metabolites revealed that lactate, butyrate, isoleucine, acetate, and $\beta$-hydroxybutyrate were increased, whereas hippurate and fumarate were decreased in milk with high levels of somatic cells.
\end{abstract}

Key words: somatic cell count, milk composition, metabolite, nuclear magnetic resonance spectroscopy

Received June 7, 2012.

Accepted October 8, 2012.

${ }^{1}$ Corresponding author: Ulrikk.sundekilde@agrsci.dk

\section{INTRODUCTION}

In many parts of the world bovine milk is an essential part of the human diet. Milk can either be consumed directly or be processed into different dairy products. Thus, the technological and nutritional properties of the milk are essential for high-quality products, and it is well known that milk composition is affected by different factors such as lactation stage, feed, genetic background, and cow health (Jakob and Puhan, 1992; Hortet and Seegers, 1998; Lock and Garnsworthy, 2003; Tsioulpas et al., 2007; Le Maréchal et al., 2011).

Mastitis inflammation can either be subclinical or clinical; subclinical mastitis is not easily detected, as no visual indicators of the inflammation exist; however, SCC is elevated, and the milk quality is affected, whereas clinical mastitis is normally associated with clinical signs in response to invading microorganisms, and consequently immune cells are attracted. Thereby, mammary epithelial cells, neutrophils, macrophages, and lymphocytes are secreted into the milk, leading to increased SCC (Sordillo et al., 1997). Somatic cell count is one of the primary parameters generally used to determine the usefulness of milk for consumption or further processing, and it greatly affects payment schemes to the primary producers. The accepted threshold for somatic cells in bulk milk in the European Union is below 400,000 cells/mL, whereas other limits are in place in the United States and Canada (Schukken et al., 2003). The major cause of elevated somatic cells in milk is the infection status of the udder or udder quarter (Harmon, 1994). Apart from profound changes in the protein profile, elevated SCC and mastitis has been associated with influx of milk metabolites (Hettinga et al., 2009). The origin of metabolites in milk is not completely clear, as they may be secreted directly by microorganisms into the milk (Hettinga et al., 2008; Hettinga et al., 2009), be secreted or leaked from live or dead immune cells, a result from an enzymatic reaction in the milk (Azzara and Dimick, 1985), be transferred to milk from blood due to increased endothelial permeability (Bannerman, 2009), or be secreted from the mammary epithelial cells (Shennan and Peaker, 
2000). Thus, the different origins contribute to the variability of milk metabolites. Several milk metabolites have been shown to derive from microorganisms (e.g., acetate, ethyl acetate, and butyrate; Hettinga et al., 2009). Furthermore, lactate is the major end product of carbohydrate metabolism and can be produced by microorganisms in milk or by anaerobic epithelial respiration in oxygen-deprived conditions following mastitis (Mayer et al., 1988). Lactose and citrate are secreted by the mammary epithelial cells by exocytosis (Shennan and Peaker, 2000). The influx of metabolites may change the technological properties of the milk, and elevated cell count in milk has been shown to affect the coagulation properties important for the cheese-making quality of the milk (Le Maréchal et al., 2011).

Recently, GC-MS was used to investigate volatile compounds in mastitic milk, and specific compounds were identified to be increased in milk by different pathogens (Hettinga et al., 2009). A technique for the analysis of metabolites in solution is nuclear magnetic resonance (NMR). Nuclear magnetic resonance-based metabonomics on biofluids, plant extracts, and food items has proven to be an excellent explorative analytical technique known for its ability to assess a metabolic footprint of an individual sample or specimen (Lindon et al., 1999; Kolokolova et al., 2008; Wishart, 2008; Kim et al., 2010). In bovine milk, NMR-based metabonomics has previously identified small molecules, which may be involved in the coagulation process, as differential amounts of choline, carnitine, citrate, and lactose in the milk correlated well with coagulation properties (Sundekilde et al., 2011). Furthermore, NMR in combination with GC-MS has been used to assess the metabolic status of cows in relation to ketosis risk (Klein et al., 2010, 2012). The objective of the present study was to investigate the potential of NMR metabonomics to assess changes in metabolite composition of milk associated with changes in milk SCC on individual milk samples from 876 cows.

\section{MATERIALS AND METHODS}

\section{Milk Samples}

Milk samples from individual cows were collected as part of the Danish/Swedish Milk Genomics Initiative. In total, 892 milk samples from Danish HolsteinFriesian $(\mathrm{n}=456)$ and Jersey cows $(\mathrm{n}=436)$ were collected from 42 nonorganic herds (Jensen et al., 2012. All cows were housed in loose housing systems, fed with TMR according to standard practice during their indoor period, and milked twice per day. Immediately after milking, milk samples were placed on ice for transport to the laboratory. Once at the laboratory, the milk samples were aliquoted, skimmed, and frozen at $-80^{\circ} \mathrm{C}$. The cows included were selected from a scheme setup to maximize the genetic variability, but still matching cows within the first-third parity and mid-lactation period (Poulsen et al., 2012). Each milk sample was analyzed for concentration of milk fat, protein, casein, and lactose using a Milkoscan FT 2 apparatus (Foss Electric A/S, Hillerød, Denmark) and for SCC using a Fossomatic 5000 apparatus (Foss Electric A/S) at Eurofins Laboratory (Holstebro, Denmark). Nuclear magnetic resonance data from 70 samples representing SCC extremes were selected for analysis of differences in specific metabolite profiles representing 2 classes of SCC (i.e., high or low SCC). The selected samples include 35 samples with SCC above $7.2 \times 10^{5}$ cells $/ \mathrm{mL}$ and 35 samples with SCC below $1.4 \times 10^{4}$ cells $/ \mathrm{mL}$.

\section{NMR Spectroscopy}

Prior to NMR spectroscopy, the 892 skim milk samples were thawed and thoroughly shaken to homogenize the samples. Subsequently, the samples were filtered to remove residual lipids and protein using an Amicon Ultra $0.5 \mathrm{~mL}$ 10-kDa cutoff spin filter (Millipore Corp., Billerica, MA) centrifuged at 10,000 $\times g$ for 15 min. A $400-\mu \mathrm{L}$ filtered sample was added to $200 \mu \mathrm{L}$ of heavy water $\left(\mathrm{D}_{2} \mathrm{O}\right)$ containing $0.025 \%$ sodium trimethylsilyl$\left[2,2,3,3-{ }^{2} \mathrm{H}_{4}\right]$-1-propionate (Sigma-Aldrich A/S, Copenhagen, Denmark) as an internal chemical shift reference. Proton $\left({ }^{\mathbf{1}} \mathbf{H}\right)$ NMR spectroscopy was performed at 298 $\mathrm{K}$ on a Bruker Avance III 600 spectrometer, operating at a ${ }^{1} \mathrm{H}$ frequency of $600.13 \mathrm{MHz}$, and equipped with a 5-mm ${ }^{1} \mathrm{H}$ TXI probe (Bruker BioSpin GmbH, Rheinstetten, Germany). The sample sequence was randomized before acquisition. Standard 1-dimensional spectra were acquired using a single $90^{\circ}$ pulse experiment with a relaxation delay of $5 \mathrm{~s}$. Water suppression was achieved by irradiating the water peak during the relaxation delay, and a total of 64 scans were collected into $32 \mathrm{~K}$ data points spanning a spectral width of $12.15 \mathrm{ppm}$. Prior to Fourier transformation, the data were multiplied by a $0.3 \mathrm{~Hz}$ line-broadening function. The ${ }^{1} \mathrm{H}$ NMR spectra were phase and baseline corrected manually using Topspin 2.1 (Bruker BioSpin). Nuclear magnetic resonance signals have been assigned in accordance with existing literature, spike experiments, 2-dimensional NMR spectroscopy, and the Human Metabolome Database $\mathrm{CHu}$ et al., 2004; Wishart et al., 2009; Klein et al., 2010). Integrals were calculated for the following metabolites using the specified well-resolved resonances; acetate, $\delta$ $1.92 \mathrm{ppm}(\mathrm{s}, 3 \mathrm{H})$; adenine, $\delta 8.12 \mathrm{ppm}(\mathrm{s}, 1 \mathrm{H})$ and 8.13 ppm (s, 1H); BHBA, $\delta 1.20 \mathrm{ppm}(\mathrm{d}, \mathrm{J}=6.29 \mathrm{~Hz}, 3 \mathrm{H})$; butyrate, $\delta 0.90 \mathrm{ppm}(\mathrm{t}, \mathrm{J}=7.30 \mathrm{~Hz}, 3 \mathrm{H})$; citrate, 2.53 $\operatorname{ppm}(\mathrm{d}, \mathrm{J}=16.51 \mathrm{~Hz}, 2 \mathrm{H})$; creatinine, $\delta 3.04 \mathrm{ppm}(\mathrm{s}$, 
$3 \mathrm{H})$; fumarate, $\delta 6.52 \mathrm{ppm}(\mathrm{s}, 2 \mathrm{H})$; hippurate, $\delta 7.84$ ppm (dd, J = 8.40 Hz, $1.46 \mathrm{~Hz}, 2 \mathrm{H}), \delta 7.64$ (tt, J = 7.42 $\mathrm{Hz}, 1.45 \mathrm{~Hz}, 1 \mathrm{H})$, and $\delta 7.54 \mathrm{ppm}(\mathrm{m}, 2 \mathrm{H})$; isoleucine, $\delta 0.93 \mathrm{ppm}(\mathrm{d}, \mathrm{J}=7 \mathrm{~Hz}, 3 \mathrm{H})$; lactate, $\delta 1.33 \mathrm{ppm}(\mathrm{d}$, $\mathrm{J}=7.10 \mathrm{~Hz}, 3 \mathrm{H})$; lactose, $\delta 5.23 \mathrm{ppm}(\mathrm{d}, \mathrm{J}=3.85 \mathrm{~Hz}$, $1 \mathrm{H})$; orotate, $\delta 6.19 \mathrm{ppm}(\mathrm{s}, 1 \mathrm{H})$; and phosphocholine, $\delta 4.17 \mathrm{ppm}(\mathrm{m}, 2 \mathrm{H})$.

\section{Uni- and Multivariate Data Analysis}

The ${ }^{1} \mathrm{H}$ NMR spectra were aligned using the icoshift tool (Savorani et al., 2010) by co-shifting of the whole spectra according to the anomeric lactose proton at $5.23 \mathrm{ppm}$. Alignment was performed in MATLAB 7.13 (MathWorks Inc., Natick, MA, USA). All ${ }^{1} \mathrm{H}$ NMR spectra were acquired at the same instrument settings. Residual water resonances, urea resonances, and resonances stemming from the filtering procedure were removed. The proton NMR spectra were subdivided into 0.04-ppm integral regions and integrated, reducing each spectrum into 242 separate variables in the regions 10.00 to $5.91,5.64$ to $5.00,4.72$ to 3.79 , and 3.60 to $0.06 \mathrm{ppm}$. Prior to multivariate data analysis, different scaling methods of the NMR variables were tested, including Pareto scaling and scaling to unit variance. Principal components analysis (PCA) was used to provide a transformation of the original variables (NMR resonances) into a substantially reduced set of uncorrelated variables (the principal components). Principal components analysis was applied to the Pareto and unit variance scaled data to explore any clustering behavior of the samples. In total, 892 samples were analyzed by NMR spectroscopy. However, based on visual inspection and multivariate data analysis, 16 samples were assigned as outliers and, consequently, 876 samples were included in the multivariate models. Furthermore, the global data were analyzed by a partial least squares (PLS) regression model to address the variation in metabolites specifically associated with SCC. Somatic cell count data was not log transformed, as the correlation between the metabolite profile and high SCC variations was of specific interest. For the analysis of the $2 \mathrm{SCC}$ classes (high or low SCC), orthogonal projection of latent structures discriminant analysis (OPLS-DA) was applied to the unit variance scaled data. Orthogonal projection of latent structures discriminant analysis is an extension of PLS, and it provides a separation of the systematic variation of NMR resonances in samples into 2 parts; one unrelated to SCC and one linear related to SCC. This is further coupled with a discriminant analysis (DA). The OPLS-DA coefficients provide a measure of how well individual NMR variables (resonances) correlate with SCC. Covariance was investigated by analysis of OPLS-DA regression coefficients back-transformed to original data and color coded by the loading weights (Cloarec et al., 2005). The multivariate data analysis was performed using SIMCA-P+ 13 (Umetrics AB, Umeå, Sweden) and PLS Toolbox 6.5 (Eigenvector Research Inc., Wenatchee, WA) software. Partial least squares and OPLS-DA models were cross-validated by dividing the samples into 7 groups and sequentially leaving 1 group out of the model. The appropriate number of components was estimated using double cross-validation. The significance level of the PLS regression was tested using ANOVA based on the cross-validated predictive residuals (CV-ANOVA; Eriksson et al., 2008). The correlation coefficient $\left(\mathbf{Q}^{2}\right)$ and root mean square error of cross validation (RMSECV) were measures of the model robustness following crossvalidation. Binning and visualization of OPLS-DA plots were performed in MATLAB 7.13 (MathWorks Inc.) using in-house-developed scripts. Univariate statistical significance was evaluated by using 1-way and 2-way ANOVA, using the Statistics Toolbox in MATLAB 7.13 (MathWorks Inc.). Moreover, the 242 spectral variables were tested for significant differences attributed to herd or breed.

\section{RESULTS \\ Multivariate Data Analysis of ${ }^{1} \mathrm{H}$ NMR Spectroscopic Profiles}

Nuclear magnetic resonance metabolite profiles of 876 milk samples were subjected to multivariate data analysis with both supervised and unsupervised methods. Unsupervised PCA was performed to investigate the global clustering behavior of the samples. The score scatter plot of the first 2 principal components (41.59 and $26.24 \%$ variance explained, respectively) of a PCA on 876 milk samples colored according to SCC is shown in Figure 1A. The PCA performed did not reveal any clustering according to either breed (not shown) or SCC (Figure 1A), indicating that the major source of variability in the data set was unrelated to breed or SCC. However, milk samples with an SCC above 2 $\times 10^{6}$ cells $/ \mathrm{mL}$ tended to be positioned at the negative area of principal component 1 (Figure 1A). The supervised PLS regression model was generated using all NMR spectra and explained $89 \%$ of the response variable (NMR features) and $82 \%$ of the SCC based on 9 PLS components, and a plot of predicted SCC versus observed SCC is shown in Figure 1B. The PLS regression model was cross-validated by dividing the samples into 7 groups and sequentially leaving 1 group out of the model. The RMSECV was $2.25 \times 10^{5}$ cells $/ \mathrm{mL}$ and the PLS regression model yielded a $\mathrm{Q}^{2}$ value of 0.76 , showing a significant correlation $(P<0.001)$ between 


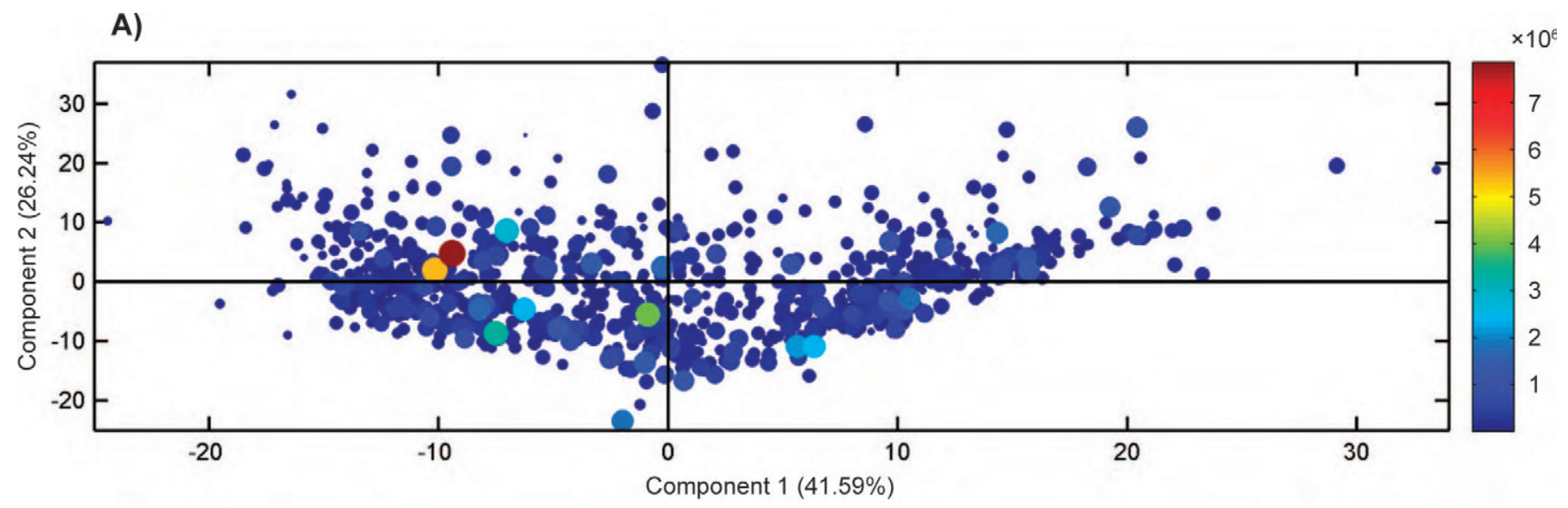

B)

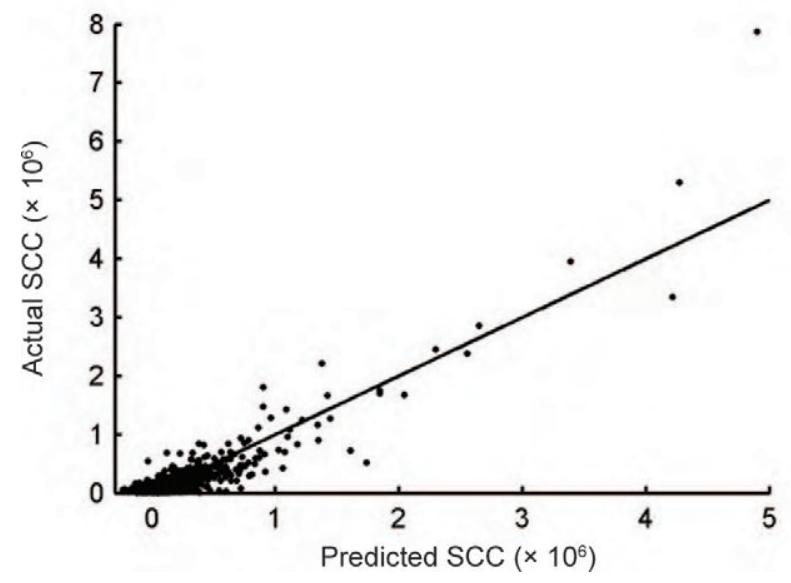

C)

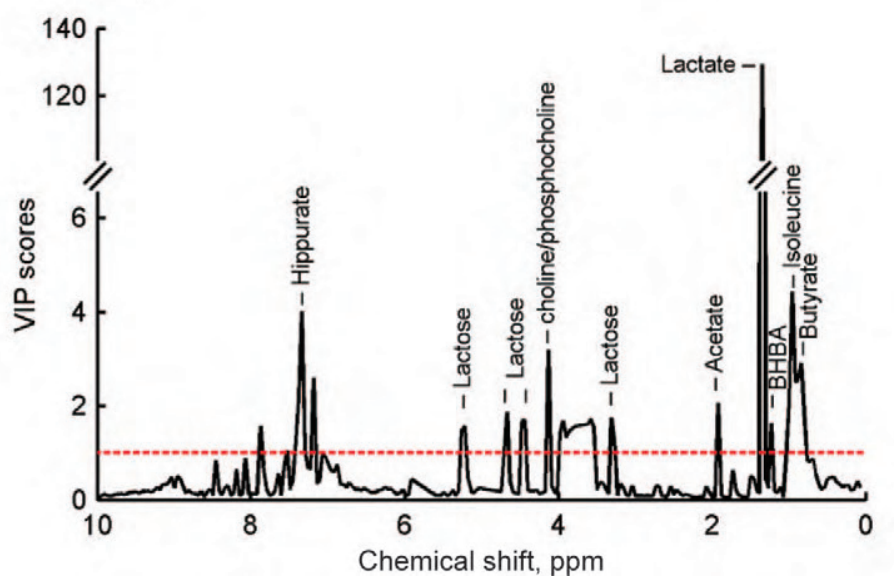

Figure 1. (A) Principal components analysis (PCA) score plot of the first 2 principal components of unit variance-scaled nuclear magnetic resonance (NMR) data $(\mathrm{n}=876)$. Sample markers are sized and colored continuously according to SCC, as indicated by the color bar. (B) Actual versus predicted plot of SCC obtained from a 9-component PLS regression model established on 876 samples $\left[\mathrm{R}^{2}=0.89\right.$, correlation coefficient $\left.\left(\mathrm{Q}^{2}\right)=0.76\right]$. (C) Corresponding variable importance in projection (VIP) score plot, giving an estimation of the importance of each variable in the partial least squares (PLS) model. A variable with a VIP score greater than 1 (dotted line) is considered important. Color version available in the online PDF.

the NMR profile of milk and SCC. To further validate the model, the samples were divided into a calibration set $(\mathrm{n}=657)$ and a test set $(\mathrm{n}=219)$ by random selection (Supplementary Figure S1, available online at http://www.journalofdairyscience.org/). The performance of the calibrated PLS model was benchmarked on its ability to predict the 219 samples, which were not included in the calibration model. The model resulted in a coefficient of determination $\left(\mathrm{R}^{2}\right)$ of the predicted SCC and the observed SCC of 0.81 and RMSECV was $2.3 \times 10^{5}$ cells $/ \mathrm{mL}$ (Supplementary Figure S1, available online at http://www.journalofdairyscience.org/). The most influential variables (metabolites) in the PLS regression model on all samples (Figure 1B) are shown by a variable importance in projection (VIP) score plot (Figure 1C). Hippurate, lactose, choline/phosphocholine, acetate, lactate, BHBA, isoleucine, and butyrate all had a VIP score above 1 and can, thus, be considered important for the ability of the PLS regression model to effectively predict SCC (Chong and Jun, 2005).

\section{${ }^{1} \mathrm{H}$ NMR Spectroscopic Profiles of Milk with Differences in SCC}

The majority of the samples had low SCC (Figure 1B). Thus, to obtain a better understanding of the main differences in the NMR profiles related to differences in SCC, 70 milk samples were selected into 2 classes for further comparison; 35 milk samples with the highest SCC (above $7.2 \times 10^{5}$ cells $/ \mathrm{mL}$ ) and 35 low SCC (below $1.4 \times 10^{4}$ cells $/ \mathrm{mL}$ ). Proton NMR median spectra of milk samples with a high or low SCC, respectively, showed a wide range of low-molecular weight metabolites (Figure 2). Overall, the milk NMR 
spectra were dominated by lactose and, thus, several resonances in the central chemical shift region of 5.23 to $3.27 \mathrm{ppm}$, thereby masking other metabolites with a chemical shift in this region. Small organic acids such as citrate, lactate, propionate, and acetate were also present in the NMR profile. Additionally, hippurate, choline, phosphocholine, carnitine, and creatinine were also observed (Figure 2). Visual comparison of the median spectra of the 2 milk classes revealed subtle differences in the profiles; particularly, lactate and acetate showed a higher relative concentration in milks with a high SCC, whereas lactose, fumarate, and hippurate showed a lower relative concentration in milk with a high SCC. An unsupervised PCA model of the 70 milk samples is shown by the score scatter plot in Figure 3A. The first 2 principal components described variation uncorrelated with SCC; however, principal component 3 was able to discriminate between the 2 groups of samples. Furthermore, the low-SCC samples showed a smaller within-group variation than the high-SCC samples (Figure 3A). To identify the latent variables contributing to the discrimination, an OPLS-DA was performed. Orthogonal projection of latent structures discriminant analysis is a supervised discriminant analysis and the systematic variation uncorrelated with SCC is removed in model. Thus, the interpretability of the model is improved as the variables associated with SCC are highlighted (Trygg and Wold, 2002). The corresponding OPLS-DA model is shown in Figure 3B. The milk samples with low SCC showed low within-group variability, whereas the high-SCC milk samples showed large within-group variability (Figure 3B). The OPLS-DA analysis was cross-validated as indicated, which generated a model with a coefficient of determination value of 0.62 and a $\mathrm{Q}^{2}$ value of 0.55 . A coefficients plot of the OPLS-DA model indicated how strongly individual NMR variables (resonances) correlate with the grouping in high or low milk SCC, and the corresponding OPLS-DA coefficients plots (Figure 4) indicated differences in lactose (Figure 4A), adenine, fumarate, orotate, hippurate (Figure 4B), acetate, lactate, BHBA, isoleucine, butyrate, and citrate (Figure $4 \mathrm{C})$. Lactose, hippurate, fumarate, orotate, and citrate had a lower concentration in milk samples with a high SCC, whereas particularly lactate had higher concentration in samples with a high SCC (Figure 4). The OPLS-DA coefficients were back-transformed from the unit variance scaling and color coded according to the OPLS-DA loading weights to improve interpretability (Cloarec et al., 2005).

\section{Relative Quantification of Selected NMR Signals}

The relative concentrations of metabolites, which were mainly indicated as important for the PLS regression in Figure 1C and for the discriminative capabilities of the OPLS-DA, were analyzed by univariate statistics comparing the mean values of the 2 subset groups. Thus, signal intensities of 13 metabolites were determined by integration of selected resonances in the NMR spectra

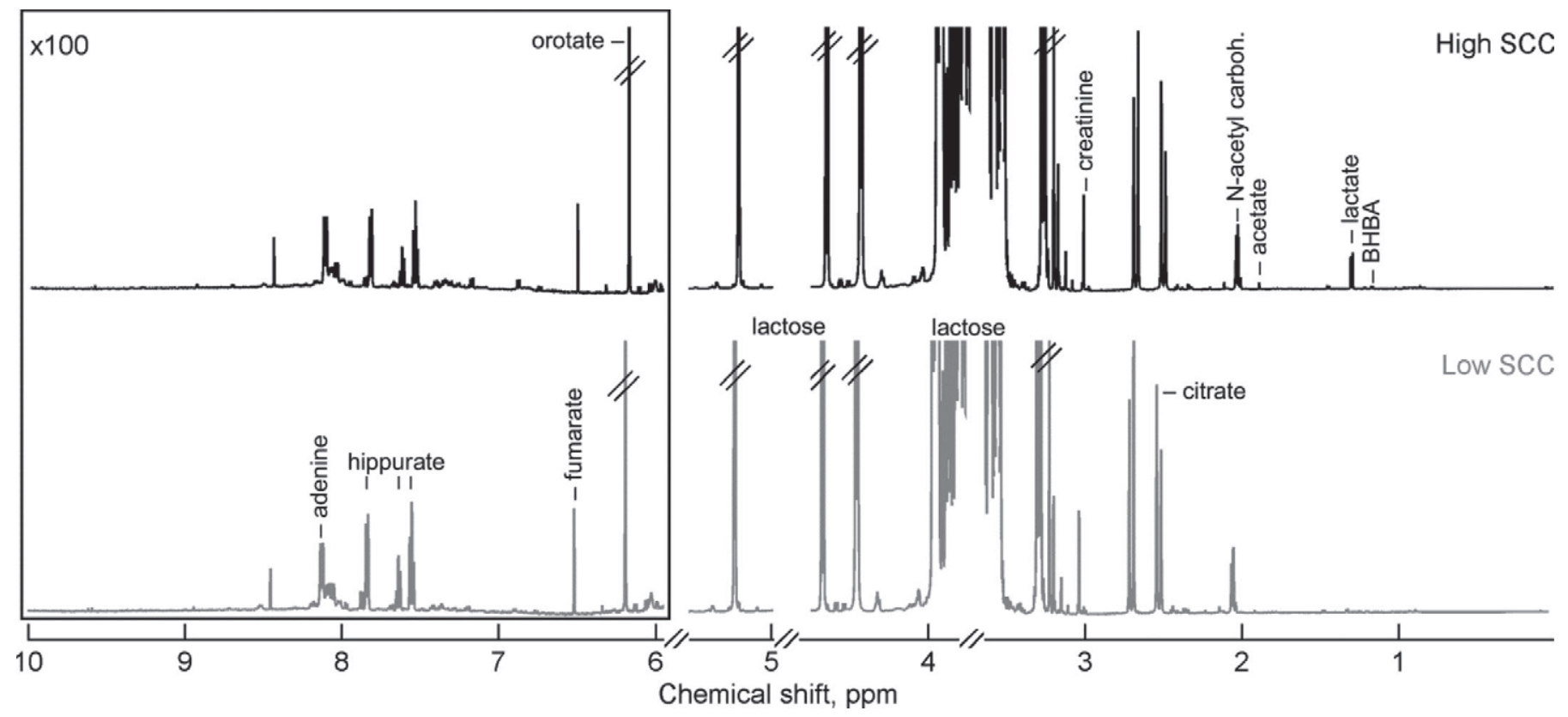

Figure 2. Median $600 \mathrm{MHz}$ proton nuclear magnetic resonance $\left({ }^{1} \mathrm{H}\right.$ NMR) spectra of $10-\mathrm{kDa}$ cutoff filtered milk with a high $\mathrm{SCC}(\mathrm{SCC}>7.2$ $\times 10^{5}$ cells $/ \mathrm{mL}$ ) or low SCC ( $\mathrm{SCC}<1.4 \times 10^{4}$ cells $/ \mathrm{mL}$ ). The spectral region of 10.0 to $6.0 \mathrm{ppm}$ is enlarged $\times 100$ compared with the spectral region 6.0 to $0.0 \mathrm{ppm}$. $\mathrm{N}$-acetyl carboh. $=\mathrm{N}$-acetyl carbohydrates. 


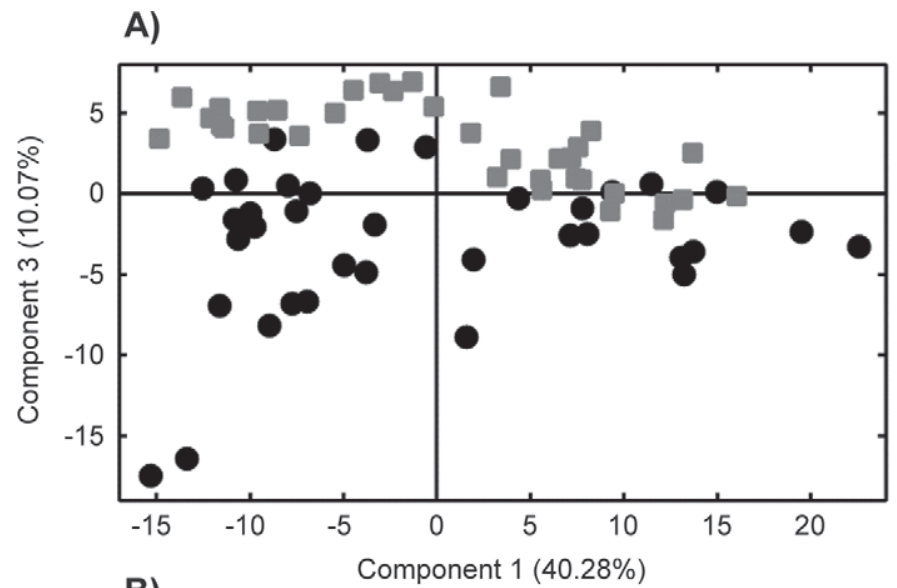

B)

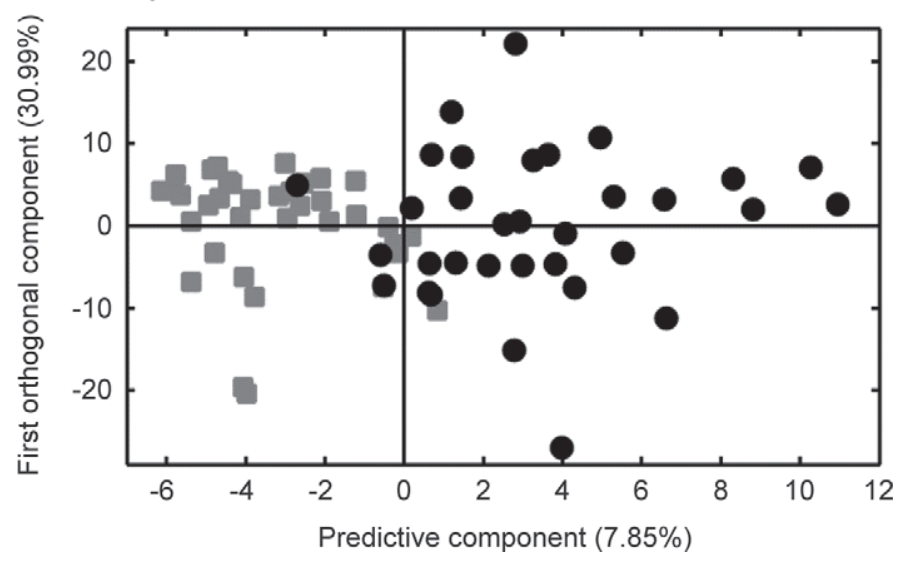

Figure 3. Supervised and unsupervised multivariate analyses of the proton nuclear magnetic resonance $\left({ }^{1} \mathrm{H}\right.$ NMR) metabolite profile of milk. (A) Principal components analysis score plot of the first and third principal components of the unit variance-scaled NMR data $(\mathrm{n}=$ 70 ); black dots represent samples with an SCC above $7.2 \times 10^{5}$ cells/ $\mathrm{mL}(\mathrm{n}=35)$ and gray squares represent samples with an SCC below $1.4 \times 10^{4}$ cells $/ \mathrm{mL}(\mathrm{n}=35)$. (B) Corresponding cross-validated orthogonal projection of latent structures discriminant analysis (OPLSDA) score plot $(n=68)$.

for the 70 selected milk samples to elucidate differences in milk metabolite profiles of low-SCC and high-SCC samples (Figure 5). The relative concentrations of metabolites have been set to 1 in low SCC samples and scaled accordingly in high-SCC samples, which means that different metabolites cannot be compared in relation to concentration. Relative concentrations of lactate $(P<0.001)$, acetate $(P=0.003)$, isoleucine $(P=0.014)$, butyrate $(P=0.024)$, and BHBA $(P<$ 0.001 ) were found to be significantly increased in milk with a high SCC. Relative concentrations of lactose $(P$ $<0.001)$, hippurate $(P=0.019)$, and fumarate $(P=$ 0.002 ) were found to be significantly decreased in milk with a high SCC. However, lactose was found to be in significant different levels in samples from different breeds and herds $(P<0.001)$, whereas acetate, lactate, isoleucine, butyrate, BHBA, hippurate, and fumarate were not significantly different between breeds or herds. Lactate was increased 12 -fold and acetate was increased 5 -fold in milk with high SCC. Furthermore, the relative concentration deduced from the NMR data of lactate showed a linear relationship with SCC (Supplementary Figure S2, available online at http://www.journalof dairyscience.org/).

\section{DISCUSSION}

\section{Data Analyses}

In this relatively large sampling of individual cow milk $(\mathrm{n}=876)$, collected samples were profiled for variations in milk compositional and technological properties as part of the Danish-Swedish Milk Genomics Initiative. In proteomics studies of the samples, milk samples with SCC $>5 \times 10^{5}$ cells $/ \mathrm{mL}$ were excluded (Jensen et al., 2012). In the present study, however, we wished to address the relations between milk metabolites and SCC, and the diversity in relation to SCC from a large number of samples is thus a strength of the study. Somatic cell count values are often log transformed; however, in the present study, the variations in the milk metabolome in samples with an SCC above $5 \times 10^{5}$ cells $/ \mathrm{mL}$ was of specific interest, and consequently SCC was not log transformed, as this would increase the importance of the metabolome variability in samples with low SCC, and decrease the importance of the metabolome variability in samples with high SCC.

The multivariate data analysis techniques used revealed distinct differences in the metabolite profiles of milk with either low or high SCC numbers. Global PCA performed on all 876 samples included in the study were unable to identify a latent variable describing milk SCC; thus, the major source of variation is unrelated to SCC. However, global PLS regression analysis showed a significant association between NMR data and SCC. Furthermore, OPLS-DA in combination with the PLS regression pinpointed the interesting NMR spectral regions, which should be examined in more detail. Therefore, the NMR metabolite profiles were useful to gain knowledge about milk metabolite covariances and correlations of metabolites related to SCC. The PLS regression model revealed a significant correlation between the milk metabolite profile and SCC. The validity of the model is emphasized by the ability of the model to accurately predict unknown samples when the sample set is split into a calibration and a validation set. Furthermore, the low RMSECV also highlight the robustness of the PLS model. However, a plot of observed versus predicted SCC reveals that below SCC of $5 \times 10^{5}$ cells $/ \mathrm{mL}$, the model is unable to predict SCC with high accuracy, whereas the model performs 

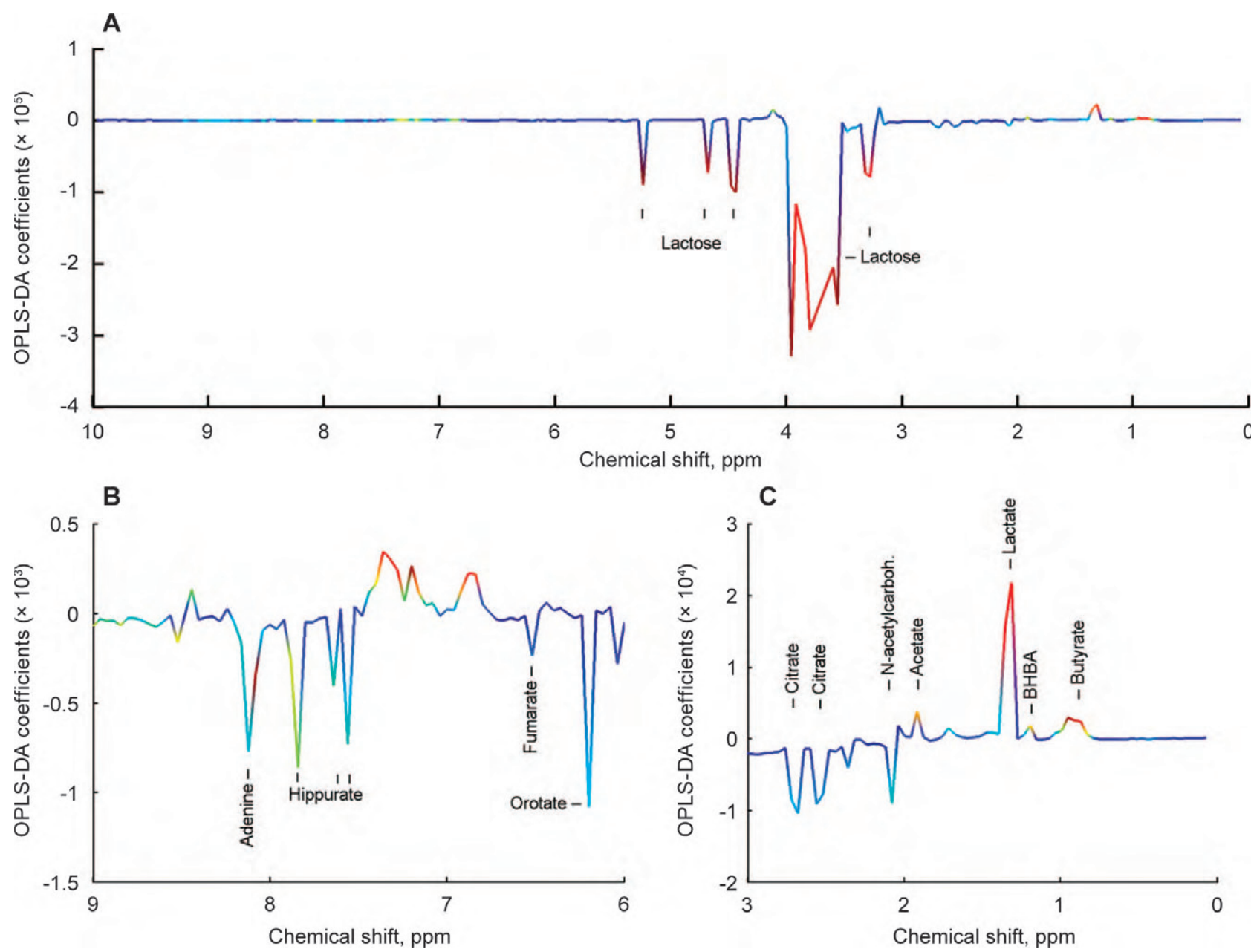

Figure 4. Orthogonal projection of latent structures discriminant analysis (OPLS-DA) coefficients plots of the unit variance-scaled model back-transformed. Each variable has been colored according to the OPLS-DA loadings [correlation between nuclear magnetic resonance (NMR) variable and SCC]. (A) Full spectral width. (B) Enlarged chemical shift region of aromatic compounds (9.0-6.0 ppm). (C) Enlarged chemical shift region of 3.0 to $0.0 \mathrm{ppm}$. N-acetyl carboh. = N-acetyl carbohydrates. Color version available in the online PDF.

better at predicting moderate to high SCC. Thus, these results indicate a natural variation in the milk metabolite profile. Biomarkers normally used in the diagnosis of mastitis are known to have natural variability in healthy cows (Åkerstedt et al., 2011). Despite this, the PLS model still pinpointed several metabolites in milk that were associated with SCC in milk as evident from the VIP plot. To identify metabolites associated with SCC, the NMR metabolite profile of a selected subset of samples with extremes in levels of SCC was further elucidated.

\section{Origins of Metabolites Differentially Expressed in Milk with Extreme SCC}

Metabolites present in milk can originate from a range of different sources, including being transferred from the blood, or being actively secreted or leaked from damaged somatic cells, from bacteria present in the milk, or secreted from the mammary epithelial cells. It has been shown that the presence of bacteria in the milk will lead to a distinct metabolic fingerprint, expressed as an increase in lactate concentration (Davis et al., 2004). A broad spectrum of pathogens may be responsible for occurrence of mastitis and the increased number of somatic cells, including Staphylococcus aureus and Escherichia coli, and different bacterial strains cause an increase in different volatile compounds (Hettinga et al., 2009). Furthermore, the range of different somatic cell types (e.g., mammary epithelial cells, neutrophils, macrophages, lymphocytes, and other cell types) all contribute to a different milk metabolite fingerprint (e.g., neutrophils are considered the first line of defense against bacterial infections and are known to secrete several defense compounds; Segal, 2005).

Analyses of NMR data using multivariate data analysis and univariate statistics showed that milk with a 


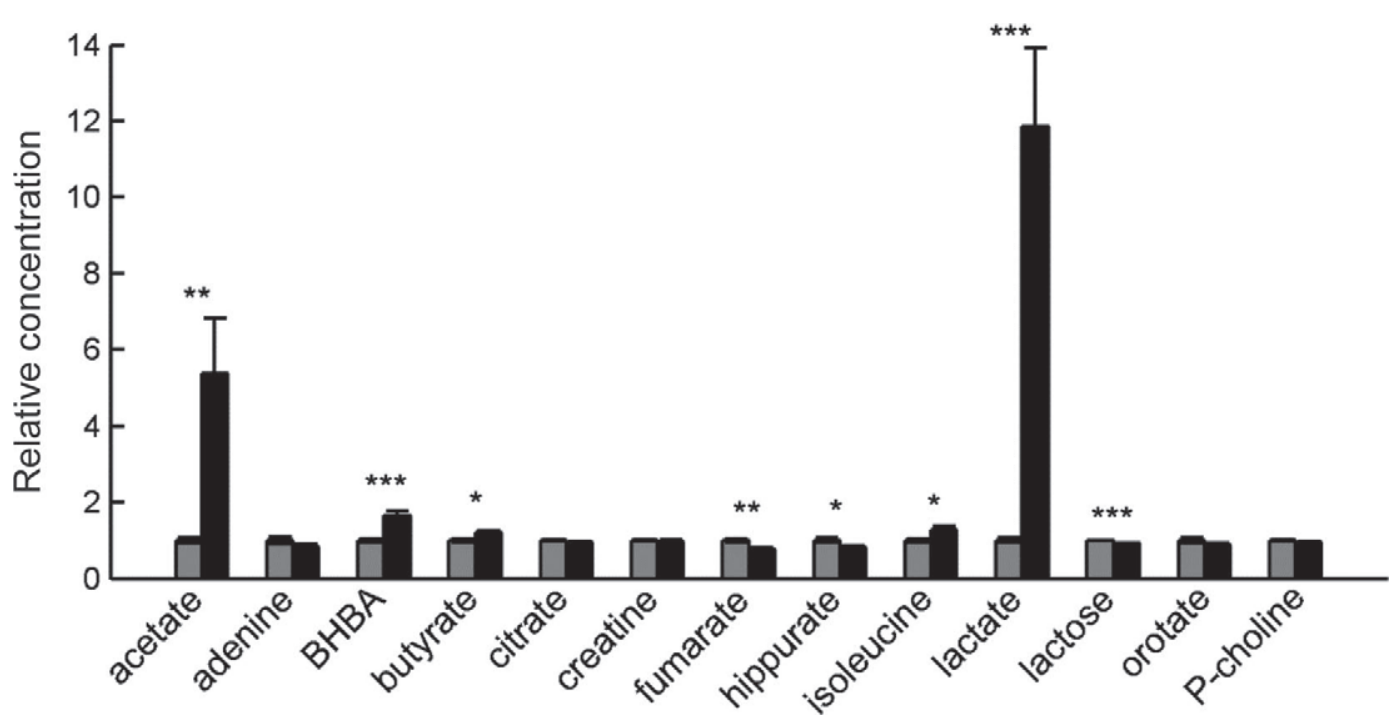

Figure 5. Relative quantification of metabolites from integration of nuclear magnetic resonance (NMR) signals. Black bars represent samples with a SCC above $7.2 \times 10^{5}$ cells $/ \mathrm{mL}(\mathrm{n}=35)$ and gray bars represent samples with a SCC below $1.4 \times 10^{4}$ cells $/ \mathrm{mL}(\mathrm{n}=35)$. Mean values \pm SEM are given. Significant differences are indicated by $* P<0.05,{ }^{*} P<0.01$, and ${ }^{* * *} P<0.001$. P-choline $=$ phosphocholine.

high SCC had significantly decreased relative amounts of fumarate, hippurate, and lactose compared with milk from cows with a high number of somatic cells. It is well known that the content of lactose is decreased in milk from ruminants with inflammation of the mammary glands, regardless of species. However, due to the fact that lactose is significantly different in both milk from Danish Holstein-Friesian and Danish Jersey samples and from the different herds, it may affect the significance levels in the present study. At high SCC or in late lactation, the mammary cell membrane is damaged and blood constituents can flow into the milk (Bannerman, 2009), and to keep the osmotic pressure constant, lactose is decreased accordingly. However, neither fumarate nor hippurate have previously been associated with elevated SCC or inflammation in general. Fumarate has previously been identified in milk by liquid chromatography-mass spectrometry (Boudonck et al., 2009), and is an intermediate of the tricarboxylic acid cycle and urea cycle. The decrease in fumarate in milk samples with a high SCC may be explained by changes in the energy metabolism in the cow due to a bacterial infection or ketosis leading to impaired tricarboxylic acid function, which in turn results in active secretion or leakage of fumarate from the mammary epithelial cells into the milk.

To our knowledge, hippurate has not previously been associated with elevated levels of milk somatic cells. However, hippurate has previously been found to be associated with feeding, as hippurate has been proposed as a marker for organic farming (Boudonck et al., 2009). Moreover, hippurate excretion in the urine has been linked to diet in humans (Bertram et al., 2007; Walsh et al., 2007; Holmes et al., 2008). Organic acids, such as the precursor of hippurate, benzoic acid, is known to inhibit the growth of some bacteria (Knarreborg et al., 2002). Hence, protective capabilities of the organic acids may be part of the explanation why we observed differences in levels of hippurate, fumarate, and orotate.

The analyses in the present study also showed that acetate, isoleucine, butyrate, and lactate were significantly increased in milk with a high SCC. Acetate and lactate are end products of bacterial metabolism. Butyrate is the most simple of the short-chain FA in milk. Acetate, butyrate, and lactate have previously been shown to be increased in high SCC milk (Davis et al., 2004; Hettinga et al., 2008; Hettinga et al., 2009). Analysis of the volatile compounds produced by 5 different bacterial species causing mastitis revealed that acetate was increased in milk from mastitic cows found to be positive for infections with Staph. aureus or E. coli (Hettinga et al., 2008). Acetate has previously been detected in milk by NMR spectroscopy in concentrations of 0.108 to $0.701 \mathrm{mmol} / \mathrm{L}$ (Klein et al., 2010). However, Klein et al. (2010) found no correlation between acetate and SCC. Isoleucine as well as hippurate has previously been found to be increased in organic milk (Boudonck et al., 2009). Cows included in the present study were exclusively from conventional farms, and the occurrence of elevated milk SCC was found to be randomized among the 42 included farms. This finding indicates that the observed changes in hippurate and isoleucine levels were not attributed to differential feeding. 
An increased lactate level indicates increased bacterial metabolism, as evident in mastitic cows. In fact, milk lactate has been shown to increase 10- to 30-fold following subclinical or clinical mastitis, respectively (Davis et al., 2004). Subclinical mastitis is not easily detected, as no visible signs of an infection exist. Interestingly, a linear correlation between relative lactate concentration and SCC was observed in the present study. Klein et al. (2010) were unable to establish a correlation between lactate and SCC based on NMR data, but the study included a limited number of cows and it is, therefore, reasonable to assume that SCC was high only in a few samples (Klein et al., 2010). Increased amounts of BHBA in milk has been shown to be related to subclinical ketosis (Geishauser et al., 2000; Enjalbert et al., 2001), and changes in the concentration of BHBA have been reported in blood of mastitic cows (Moyes et al., 2009). Moreover, Milk BHBA levels are closely correlated with blood BHBA (Enjalbert et al., 2001). However, to our knowledge, no studies have reported a correlation between BHBA and milk SCC.

\section{CONCLUSIONS}

The present study revealed that NMR-based metabolomics of milk could identify that the levels of 8 metabolic compounds were significant different in milk with high or low SCC. It is well known that milk composition is affected by elevated SCC, including increases in whey proteins and proteins related to the immune system, and also changes caused by an increase in proteolysis (Verdi et al., 1987). In the present study, we showed that multiple metabolites were affected when SCC was increased. This can be caused by the metabolites being transferred from the blood, from epithelial cells due to changed metabolism/synthesis, or secreted by somatic cells or bacteria. In conclusion, the present study identified novel indicators for elevated SCC in bovine milk, which may be used in the discrimination of milk quality, have potential in the diagnosis of mastitis, or as a measure of when milk should be discarded. In addition, the explorative NMR metabonomic approach confirmed previously identified biomarkers related to SCC such as lactate and acetate. Furthermore, novel metabolites hippurate, isoleucine, butyrate, fumarate, and BHBA were found to be associated with SCC.

\section{ACKNOWLEDGMENTS}

The authors thank the Danish Strategic Research Council (Copenhagen, Denmark) for financial support through the project "Milk Genomics - Impact of genes for variation in milk composition and quality," which is part of the Danish-Swedish Milk Genomics initia- tive as well as the Danish Research Council Technology and Production Sciences (FTP) for financial support through the project "Advances in food quality and nutrition research through implementation of metabolomic strategies." Furthermore, the authors thank Arla Foods amba (Viby J, Denmark) and the Danish Cattle Federation (Aarhus, Denmark) for financial support.

\section{REFERENCES}

Åkerstedt, M., L. Forsbäck, T. Larsen, and K. Svennersten-Sjaunja. 2011. Natural variation in biomarkers indicating mastitis in healthy cows. J. Dairy Res. 78:88-96.

Azzara, C. D., and P. S. Dimick. 1985. Lipolytic enzyme activity of macrophages in bovine mammary gland secretions. J. Dairy Sci. 68:1804-1812.

Bannerman, D. D. 2009. Pathogen-dependent induction of cytokines and other soluble inflammatory mediators during intramammary infection of dairy cows. J. Anim. Sci. 87(Suppl.):10-25.

Bertram, H. C., C. Hoppe, B. O. Petersen, J. Ø. Duus, C. Mølgaard, and K. F. Michaelsen. 2007. An NMR-based metabonomic investigation on effects of milk and meat protein diets given to 8-year-old boys. Br. J. Nutr. 97:758-763.

Boudonck, K. J., M. W. Mitchell, J. Wulff, and J. A. Ryals. 2009. Characterization of the biochemical variability of bovine milk using metabolomics. Metabolomics 5:375-386.

Chong, I.-G., and C.-H. Jun. 2005. Performance of some variable selection methods when multicollinearity is present. Chemometr. Intell. Lab. Syst. 78:103-112.

Cloarec, O., M. E. Dumas, J. Trygg, A. Craig, R. H. Barton, J. C. Lindon, J. K. Nicholson, and E. Holmes. 2005. Evaluation of the orthogonal projection on latent structure model limitations caused by chemical shift variability and improved visualization of biomarker changes in ${ }^{1} \mathrm{H}$ NMR spectroscopic metabonomic studies. Anal. Chem. 77:517-526.

Davis, S. R., V. C. Farr, C. G. Prosser, G. D. Nicholas, S. A. Turner, J. Lee, and A. L. Hart. 2004. Milk L-lactate concentration is increased during mastitis. J. Dairy Res. 71:175-181.

Enjalbert, F., M. C. Nicot, C. Bayourthe, and R. Moncoulon. 2001. Ketone bodies in milk and blood of dairy cows: Relationship between concentrations and utilization for detection of subclinical ketosis. J. Dairy Sci. 84:583-589.

Eriksson, L., J. Trygg, and S. Wold. 2008. CV-ANOVA for significance testing of PLS and OPLS ${ }^{\circledR}$ models. J. Chemometr. 22:594-600.

Geishauser, T., K. Leslie, J. Tenhag, and A. Bashiri. 2000. Evaluation of eight cow-side ketone tests in milk for detection of subclinical ketosis in dairy cows. J. Dairy Sci. 83:296-299.

Harmon, R. J. 1994. Physiology of mastitis and factors affecting somatic cell counts. J. Dairy Sci. 77:2103-2112.

Hettinga, K. A., H. J. F. van Valenberg, T. J. G. M. Lam, and A. C. M. van Hooijdonk. 2008. Detection of mastitis pathogens by analysis of volatile bacterial metabolites. J. Dairy Sci. 91:3834-3839.

Hettinga, K. A., H. J. F. van Valenberg, T. J. G. M. Lam, and A. C. M. van Hooijdonk. 2009. The origin of the volatile metabolites found in mastitis milk. Vet. Microbiol. 137:384-387.

Holmes, E., R. L. Loo, J. Stamler, M. Bictash, I. K. S. Yap, Q. Chan, T. Ebbels, M. De Iorio, I. J. Brown, K. A. Veselkov, M. L. Daviglus, H. Kesteloot, H. Ueshima, L. Zhao, J. K. Nicholson, and P. Elliott. 2008. Human metabolic phenotype diversity and its association with diet and blood pressure. Nature 453:396-400.

Hortet, P., and H. Seegers. 1998. Calculated milk production losses associated with elevated somatic cell counts in dairy cows: Review and critical discussion. Vet. Res. 29:497-510.

Hu, F., K. Furihata, M. Ito-Ishida, S. Kaminogawa, and M. Tanokura. 2004. Nondestructive observation of bovine milk by NMR spectroscopy: Analysis of existing states of compounds and detection of new compounds. J. Agric. Food Chem. 52:4969-4974. 
Jakob, E., and Z. Puhan. 1992. Technological properties of milk as influenced by genetic polymorphism of milk proteins - A review. Int. Dairy J. 2:157-178.

Jensen, H. B., J. W. Holland, N. A. Poulsen, and L. B. Larsen. 2012. Milk protein genetic variants and isoforms identified in bovine milk representing extremes in coagulation properties. J. Dairy Sci. 95:2891-2903.

Kim, H. K., Y. H. Choi, and R. Verpoorte. 2010. NMR-based metabolomic analysis of plants. Nat. Protoc. 5:536-549.

Klein, M. S., M. F. Almstetter, G. Schlamberger, N. Nürnberger, K. Dettmer, P. J. Oefner, H. H. D. Meyer, S. Wiedemann, and W. Gronwald. 2010. Nuclear magnetic resonance and mass spectrometry-based milk metabolomics in dairy cows during early and late lactation. J. Dairy Sci. 93:1539-1550.

Klein, M. S., N. Buttchereit, S. P. Miemczyk, A. K. Immervoll, C. Louis, S. Wiedemann, W. Junge, G. Thaller, P. J. Oefner, and W. Gronwald. 2012. NMR metabolomic analysis of dairy cows reveals milk glycerophosphocholine to phosphocholine ratio as prognostic biomarker for risk of ketosis. J. Proteome Res. 11:1373-1381.

Knarreborg, A., N. Miquel, T. Granli, and B. B. Jensen. 2002. Establishment and application of an in vitro methodology to study the effects of organic acids on coliform and lactic acid bacteria in the proximal part of the gastrointestinal tract of piglets. Anim. Feed Sci. Technol. 99:131-140.

Kolokolova, T. N., O. Y. Savel'ev, and N. M. Sergeev. 2008. Metabolic analysis of human biological fluids by H-1 NMR spectroscopy. J. Anal. Chem. 63:104-120.

Le Maréchal, C., R. Thiéry, E. Vautor, and Y. Le Loir. 2011. Mastitis impact on technological properties of milk and quality of milk products - A review. Dairy Sci. Technol. 91:247-282.

Lindon, J. C., J. K. Nicholson, and J. R. Everett. 1999. NMR spectroscopy of biofluids. Annu. Reports NMR Spectrosc. 38:1-88.

Lock, A. L., and P. C. Garnsworthy. 2003. Seasonal variation in milk conjugated linoleic acid and $\Delta^{9}$-desaturase activity in dairy cows. Livest. Prod. Sci. 79:47-59.

Mayer, S. J., A. E. Waterman, P. M. Keen, N. Craven, and F. J. Bourne. 1988. Oxygen concentration in milk of healthy and mastitic cows and implications of low oxygen tension for the killing of Staphylococcus aureus by bovine neutrophils. J. Dairy Res. 55:513-519.

Moyes, K. M., T. Larsen, N. C. Friggens, J. K. Drackley, and K. L. Ingvartsen. 2009. Identification of potential markers in blood for the development of subclinical and clinical mastitis in dairy cattle at parturition and during early lactation. J. Dairy Sci. 92:5419-5428.
Poulsen, N. A., F. Gustavsson, M. Glantz, M. Paulsson, L. B. Larsen, and M. K. Larsen. 2012. The influence of feed and herd on fatty acid composition in 3 dairy breeds (Danish Holstein, Danish Jersey, and Swedish Red). J. Dairy Sci. 95:6362-6371.

Savorani, F., G. Tomasi, and S. B. Engelsen. 2010. icoshift: A versatile tool for the rapid alignment of 1D NMR spectra. J. Magn. Reson. 202:190-202.

Schukken, Y. H., D. J. Wilson, F. Welcome, L. Garrison-Tikofsky, and R. N. Gonzalez. 2003. Monitoring udder health and milk quality using somatic cell counts. Vet. Res. 34:579-596.

Segal, A. W. 2005. How neutrophils kill microbes. Annu. Rev. Immunol. 23:197-223.

Shennan, D. B., and M. Peaker. 2000. Transport of milk constituents by the mammary gland. Physiol. Rev. 80:925-951.

Sordillo, L. M., K. Shafer-Weaver, and D. DeRosa. 1997. Immunobiology of the mammary gland. J. Dairy Sci. 80:1851-1865.

Sundekilde, U. K., P. D. Frederiksen, M. R. Clausen, L. B. Larsen, and H. C. Bertram. 2011. Relationship between the metabolite profile and technological properties of bovine milk from two dairy breeds elucidated by NMR-based metabolomics. J. Agric. Food Chem. 59:7360-7367.

Trygg, J., and S. Wold. 2002. Orthogonal projections to latent structures (O-PLS). J. Chemometr. 16:119-128.

Tsioulpas, A., A. S. Grandison, and M. J. Lewis. 2007. Changes in physical properties of bovine milk from the colostrum period to early lactation. J. Dairy Sci. 90:5012-5017.

Verdi, R. J., D. M. Barbano, M. E. Dellavalle, and G. F. Senyk. 1987. Variability in true protein, casein, nonprotein nitrogen, and proteolysis in high and low somatic cell milks. J. Dairy Sci. 70:230-242.

Walsh, M. C., L. Brennan, E. Pujos-Guillot, J. L. Sébédio, A. Scalbert, A. Fagan, D. G. Higgins, and M. J. Gibney. 2007. Influence of acute phytochemical intake on human urinary metabolomic profiles. Am. J. Clin. Nutr. 86:1687-1693.

Wishart, D. S. 2008. Metabolomics: Applications to food science and nutrition research. Trends Food Sci. Technol. 19:482-493.

Wishart, D. S., C. Knox, A. C. Guo, R. Eisner, N. Young, B. Gautam, D. D. Hau, N. Psychogios, E. Dong, S. Bouatra, R. Mandal, I. Sinelnikov, J. Xia, L. Jia, J. A. Cruz, E. Lim, C. A. Sobsey, S. Shrivastava, P. Huang, P. Liu, L. Fang, J. Peng, R. Fradette, D. Cheng, D. Tzur, M. Clements, A. Lewis, A. De Souza, A. Zuniga, M. Dawe, Y. Xiong, D. Clive, R. Greiner, A. Nazyrova, R. Shaykhutdinov, L. Li, H. J. Vogel, and I. Forsythe. 2009. HMDB A knowledgebase for the human metabolome. Nucleic Acids Res. 37(Suppl. 1):D603-D610. 